\title{
Navigation and learning style
}

\author{
Gwyn Brickell \\ University of Wollongong
}

"I've heard and forgotten.

I've seen and remembered. I've done and understood." (old Chinese proverb)

\section{Introduction}

As one of the most recent developments in Information Technology, interactive multimedia technology stands to offer a particularly significant contribution to the improvement of education and training. Sound, direct manipulation of interface objects (such as menus, tools, or instructional screens), visualisation of processes and dynamic video images are all features of today's interactive multimedia systems. The technology can not only be used to improve the quality of instruction, but more significantly it can also be used by learners to achieve a variety of learning objectives.

Interactive multimedia provides the stimulation for students to be actively involved in their learning. They can be encouraged to think for themselves to gain a better understanding of the content material. Despite the promises, if such sophisticated systems are not well designed they can create problems in terms of the cognitive demands they place upon the learner and by inadequately supporting changes in individual and group working practices (Preece \& Davies, 1992).

The development of multimedia systems promises to enhance learning and to enable users to interact with information in new ways. However, little attention has been paid to the complexity of the interaction of design strategies and learners' characteristics (Lee, 1992).

A review of the literature indicates some disagreement between researchers in the link between learning style and the effective application 
of computer assisted learning to learners' achievement. Despite many years of study, there are no adequate learning theories upon which to base the design of multimedia systems (Wright, 1989). The idea, as Merrill $(1973,1975)$ and Frederico (1980) have proposed, is that students will make their own decisions throughout the program so as to match their own learning styles, personalities, or other relevant traits (Williams, 1993). Instructional design theories largely remain to be tested empirically, and none of the theories proposed to date have proved to be universally adequate (Stanton \& Stammers, 1990).

Others suggest that learning style can play an important role in how fast and how well overall learning will occur when navigating in a hypertext environment (Stanton \& Baber, 1992; Williams, 1992; Bartolome, 1993; Beasley \& Villa, 1992; Dunn, Beaudry \& Klavas, 1989). Jonassen (1988) suggests that researchers should identify any prominent access path learners take and relate these to holistic learning styles.

Navigation is becoming one of the most important design issues in interactive multimedia. As interactive multimedia courseware is designed to impart knowledge, the more information presented to the user, the more powerful the navigation scheme needs to be.

\section{Learning style}

Learning style is a biologically and developmentally imposed set of personal characteristics that make the same teaching/learning strategy effective for some and ineffective for others. Davidson (1990) suggests that learning style refers to "an individual's characteristic mode of gaining, processing, and storing information". De Bello (1990) suggests that learning style refers to "the way people absorb, process and retain information".

Instructional design research needs to investigate questions about learners and their characteristics in order to determine what type of delivery instruction is best for which type of learner in what type of environment (Orr \& Davidson, 1992). Since research into learning styles suggests that individuals learn differently, it is logical then that some learners would prefer to learn individually, while others would prefer to learn from interaction in groups.

Learning styles have been categorised by various researchers in the field including Kolb, Rubin, and McIntyre (1979), Lotas (1979), Fischer and Fischer (1979), McCarthy (1981), Gregorc (1982) and Taggart and Torrance (1984) (Schmeck, 1988).

Kolb and Wolfe (1979) present an Experiential Learning Cycle and in describing the model, suggest that learning requires abilities that are polar 
opposites. Learners need to choose which set of learning abilities that they will bring to a specific situation. Wolfe and Kolb cite the work of cognitive psychologists such as Piaget, Bruner, Harvey, Hunt and Shroeder who have identified the concrete-abstract continuum as the main dimension along which human cognitive growth occurs. He suggests that the active mode is based on seeking reward for accomplishment and the reflective mode on seeking reward through avoidance of error. Engagement in one mode reduces the other.

Kolb (1976) devised a self descriptive instrument entitled the Learning Styles Inventory (LSI), and using this tool, identified four statistically prevalent types of learning styles:

- Convergers - value abstract conceptualisation over concrete experience and are active experimenters. Their strength is the practical application of ideas. They prefer things to people and have the ability to focus in on a specific problem.

- Divergers - value concrete experience and reflective observation. They have the ability to view concrete experiences from a number of perspectives.

- Assimilators - value abstract conceptualisation and reflective observation and hence have the ability to formulate theories. They have strong inductive reasoning abilities and prefer abstract concepts to people.

- Accommodators - value concrete experience and active experimentation, hence are willing to take risks. Their strength is the ability to adapt to immediate circumstances. Accommodators are at ease with people but may appear pushy or impatient.

Wolfe and Kolb discuss the concept of a "learning press" which is described as adaptive behaviour of individuals, in complex situations, based on the learning processes employed. A particular environment may enhance the processes associated with a learning style resulting in engagement or, in a complex environment, the learning style of the individual may result in withdrawal from the learning experience. This concept has implications for design of navigation systems to ensure there are educationally sound verbal, iconic and holistic options available to the user.

Claxton and Murrell (1987) present a selection of learning style models that help identify how learners interact with and acquire knowledge from their environment. They are classified into the following categories:

\author{
personality \\ information processing \\ social interaction \\ instructional preference
}


Various researchers (Orr \& Davidson, 1992; Williams, 1992; Stanton \& Baber, 1992) have conducted correlational studies between these models and a range of learners' characteristics, often with conflicting results.

The Constructivists argue that knowledge is constructed only in the minds of the learner. The theory holds that constructivism is facilitated by having the learner identify topics or issues, locate resources, plan investigations and activities, practise self-evaluation and formulate principles (Volker, 1992). The process of learning involves the construction of meanings by the learner from what is demonstrated or experienced. Constructivists deemphasise instruction and performance and place far more responsibility for deciding what and how to learn on the student (Hedberg, Harper, Brown, 1993).

In the design of interactive multimedia material, a more enriched learning experience occurs when learners are presented with different styles of learning in both content and teaching style. If learners are able to determine their own pathway in selecting the information available to them, in the manner that best suits their own learning style, then the whole learning process may be more efficient.

The challenge for designers of interactive multimedia applications is in the identification of learning styles as a basis for providing responsive instruction for the user in a diverse student population.

\section{Navigation}

Because of differences in the way individual learners seek information and acquire knowledge they develop unique styles for accessing and relating to the information available for discovery. These differences may describe how they prefer to interrelate, which mode of navigation they prefer for accessing information, how they recognise new information, or the sequence in which they prefer to gather the information. As a consequence, navigation is becoming one of the most important design issues in interactive multimedia development. As suitable courseware is designed to impart knowledge, the more information presented in any package, the more powerful the navigation system needs to be.

Tucker (1990), in defining navigation for the interactive multimedia environment, draws an interesting analogy with navigation at sea. The seas, throughout the history of exploration, have been charted and defined. Some of these charts are of different scales and provide different information about the landfalls, current and dangerous reefs. Ships set sail with all this information at hand and as long as they were in sight of land, it was an easy matter to navigate. 
All this changed however when the ships went beyond the coastal waters. Even with all the available information, situations arose where one could only rely on "dead reckoning", or that "gut feeling" one may have. Navigation became much more difficult because the objects which the sailors now turned to for aid, depended on computations involving the sun and stars. Consultation with the appropriate tables provided an estimation of location. Much more information and many less variables had to be taken into account but navigation was supposedly more sure.

"Yet, ships still collide, run aground, get stuck on sandbars, or just get plain lost" (Tucker, 1990). With each passing year, more sophisticated guidance systems are developed and one may eventually expect to see the situation where the ships are automatically guided from place to place.

After many years of using computer software through which the user is "channelled in fixed paths" as a result of both hardware limitations and the designer's imagination, or lack of it, one finds that designers are now presenting the learner with "fully charted seas" on which the learner can "set sail" in whatever direction they want. In well designed software, the navigational aids are all there and easy to use. Users still get lost or get stuck because the user must still interpret the navigational aids, many of which may be more inhibiting rather than helpful due to their complexity.

Hooper (1988) suggests "... people have begun to discover that navigation through information space is a major issue, as users can be easily confused about just where they are, and, are frequently unable to determine how to get somewhere they want to be."

There is a temptation then to try to counter this by providing all sorts of analogies to real world navigational aids. However, if one is not to jeopardise the learning process by increasing cognitive load, one must show restraint and instead, base one's system of navigation on as simple a model as possible. Therefore, in the design process, it would seem to be more important to develop a suitable metaphor(s) to link the ideas presented to the user, through a variety of navigational options.

Simplicity in navigation is essential because most people are poor navigators in the "real world", particularly with respect to three dimensional systems and as Hooper (1988) suggests, this is compounded by the realisation that people are also very poor map readers. This is further exacerbated by the fact that in multimedia environments one is dealing with an open-ended environment where the learner may explore a range of pathways in seeking information, thus increasing the possibility of "running aground".

Apple Computer Inc (1990) defines navigation as the "... stack user interface by which users move around within the stack". It is also 
suggested that navigation represents the most important component in successful hypermedia design. Most people learn by doing and therefore, learning cannot be totally effective if the user is prevented from completing the task for whatever reason, be it by virtue of "getting lost" or becoming frustrated and giving up.

Whatever the case, the key to the problem of navigation is users should believe that it should be simple and intuitive. It is suggested by Hedberg (1989) that the "... current enthusiasm for HyperCard... or any hypermedia based system... as a medium for exploration... centred learning environments... is based on the ability of the keen learner to choose a path and enjoy the options". This can only be so if the navigation of the system is simple and intuitive so as not to increase the level of cognition required to deal with the decisions which must be made during exploration.

In general, the less users have to think about where they are or what to do next, the more they can concentrate on the subject matter being presented, and hence the more complete their learning. (Apple Computer Inc, 1990)

If one is to be able to achieve this, then the cognitive load imposed on the navigator should be minimised and learning enhanced. (This is also linked to the skills/confidence developed by the user through gaining experience in using the software).

Simply, one may define navigation as, the art of knowing where one is! The user must make decisions as to where they wish to go and what they wish to investigate. Whatever the decision made, the navigational interface must address the following needs:

- How to get where one wants to go and how to move around.

- How to get back to where one was.

- The necessity to know where one is within the system.

Finally, "... fundamental to the entire field of cognition is the finding that unless people engage a task, they will not learn from it" (Ambron \& Hooper, 1988). One must therefore make sure that the task is not "lost" because of poor navigational cues. "Basic research in cognition supports the notion that multimedia presentations should be highly effective in learning." (Ambron \& Hooper, 1988), but one must take care that all the "special tricks" and complex pathways used to present many hypermedia packages, do not negate their usefulness by inducing cognitive overload. Sweller (1988) makes the point that the more steps needed to "get somewhere" or produce some outcome, and the more items that have to be matched in order to decide between actions, the greater will be the cognitive load. 


\section{Design model examples}

Effective navigation systems can facilitate the understanding of a user's learning sequence and reduce the problems of poor concept development (Hedberg, 1993). To enable the development of effective navigational system a number of approaches have been proposed, using a design metaphor(s) to link the main ideas and concepts, before the navigation system is designed.

In producing design models for interactive multimedia, Apple Computer Inc (1989) suggests five basic tenets of effective navigation that need to be understood and used as a basis for not only the selection of navigational devices, but also in the design of the navigational system:

- What's in the package?

- Where am I now?

- Where can I go from here?

- How do I get there?

- Where have I already been?

"The navigation system... or tools... one uses will depend on the characteristics of the intended users, the subject matter and the style of presentation". There have been a number of design models of interactive multimedia produced, most of which have not only used effective instructional design but have made good use of the unique features of the technology and have emphasised student based inquiry techniques. Early examples of interactive multimedia design include Animal Pathfinders, Life Story and The Mystery of the Disappearing Ducks. A recent development, Investigating Lake Iluka, combines a range of multimedia resources in supporting new learning pathways. With each of these design models there is a graphical presentation that links the learning task to the navigational system.

Animal Pathfinders was developed (by Apple Computer Inc) and modified around an existing nature film. The structure for the interactive development of this material is based on three main access methods, ie. use of film resources, access to database material via a "data cube" and activities for the classroom. Navigation is provided through the use of icons in the data cube as well as via a menu selection map.

Life Story (by Apple Computer Inc) is also based around an existing movie. This design model features the discovery of DNA by Watson and Crick. The navigation system employed in this design model involves a "pilot map" linking two competing teams of researchers around a time line metaphor using the two arms of the DNA molecule. The user can follow the development of the research leading to the discovery, view video segments, access background information. All stacks in the database have the same structure thus helping to reduce the cognitive load. 
The Mystery of the Disappearing Ducks (developed by Apple Computer Inc, Lucasfilm, National Audubon Society) is a story based on an ecological crisis. The focus of the metaphor is a fictional character, Paul Parkranger. Paul's office provides a context for students to gather information concerning the mystery by accessing multimedia resources available in the room. Additional information is provided by Paul via a picturephone or telephone. The package uses inquiry and problem solving techniques in developing a broad range of investigative skills in the user.

Investigating Lake Iluka (by University of Wollongong, Apple Computer Australia, Dept of School Education) is based on a fictional lake environment where students are introduced to various ecosystems, collect information, view video segments, listen to radio reports and take physical, chemical and biological measurements of the lake environment. A "notebook" metaphor allows the user to record information and save their information to disc for later use. The navigation system has been designed in an effort to minimise the cognitive load for the user as they control their learning strategies and create new learning paths within the simulation.

Navigational aids include:

- use of colour to identify the area or major learning path

- simple use of contextual clues and regular use of a standard format of basic word style

- written directions which appear in separate areas or windows to the information required to learn the underlying concepts.

- the use of icons to provide standard support for navigation and learning.

- learning pathways that can be modified by the learner.

- a map which provides the user with information about the content of the stack under investigation

- provision of a HELP screen incorporating audio/visual explanations

- effective screen designs that clearly indicates the ecosystem under investigation.

These aids have been incorporated in a number of design metaphors to assist the user in their navigation throughout the content material. This in turn may alleviate some of the cognitive load some users experience in using multimedia environments. These metaphors include:

- a "Field Study Centre" where the user may access the multimedia resources of the package: that is view/edit newspaper reports, view videotape material or listen to radio reports dealing with lake issues. Additional textual material is available through a reference Book and an Animal and Plants Book. 
- an information "notebook" that allows users to navigate through a series of interrelated aspects of the program by selecting appropriate tabs linked to several branches within the program.

- specific graphical representation for each ecosystem which is clearly tied to the content material. This enables the user to Read, Explore, Measure, within the ecosystem under investigation.

The program has been developed using an instructional design that is both branched and linear in format. Users can navigate as if they were using a textbook (sequential navigation) or they can navigate through the material in a more exploratory fashion (hierarchical navigation). Preliminary observation of students using the program indicate that they use a combination of both navigational systems in facilitating a better understanding of the content. Whether the degree to which individual learners access the information is a function of learning style has yet to be determined and will be the subject of further study.

\section{Conclusion}

Existing research suggests that the development of computer based instructional programs should take into account both

- students' learning style(s), "Teachers should be encouraged to assess learning styles of their students in order to design instructional strategies for optimal learning" (Lee, 1992) and

- clear navigational aids, "... learners should not be so distracted by the medium that they are unable to concentrate on the material to be learnt" (Stanton \& Baber, 1992).

With the increasing development in the field of CD-ROM technology greater emphasis is being placed on a multimedia approach to education based on a learner-centered exploration of the information landscape. The presentation of cross-referenced information supported by graphic images, animation, video and sound segments entertain the user, providing motivation as well as encouraging further exploration of the content. The effectiveness of the instructional design of these multimedia applications, in terms of student learning outcomes, has yet to be assessed. The challenge for today's educators is to design and develop instructional multimedia applications that have flexibility in the navigation and cater for individual students' learning style(s). 


\section{Bibliography}

Ambron, S. \& Hooper, K. (1989). Interactive Multimedia: Visions of Multimedia for Developers, Educators and Information Providers. Washington: Microsoft Press.

Apple Computer Inc.(1989). HyperCard Stack Design Guidelines. Cupertino, CA: Apple Computer Inc.

Bartolome, A. R. (1993). Learning styles: interactivity levels and path control. Proceedings of Association for Educational Communications and Technology. (15th ed) pp 52-59.

Beasley, R. E., \& Vila, J. A. (1992). The identification of navigation patterns in a multimedia environment: A case study. Journal of Educational Multimedia and Hypermedia, 1, 209-222.

Claxton, C \& Murrell, P. (1987). Learning Styles: Implications for improved educational practice. Washington, DC: Association for the Study of Higher Education.

De Bello, T. (1990). Comparison of eleven major learning styles models: Variables, appropriate populations, validity of instrumentation, and the research behind them. Journal of Reading, Writing and Learning Disabilities International, 6(3), 203-222.

Dunn, R., Beaudry, J. \& Klavas, A. (1989). Survey of research on learning styles. Educational Leadership, 46(6), 50-58.

Harper, B. M., Hedberg, J. G. \& Brown, C. (1992). Interactive Multimedia and Information Landscapes in Science Education. Paper presented to ASCILITE Conference, University of Technology, Sydney, Australia.

Hedberg, J. G. (1989). The Relationship Between Technology and Mathematics Education: Implications for Teacher Education. University of New South Wales.

Hedberg, J. G. (1993). Design for Interactive Multimedia. Audio Visual International, 1(6), 11-14.

Hedberg, J. G., Harper, B. M. \& Brown, C. (1993). Navigating through Multimedia Design to reduce Cognitive Load. Interactive Learning International, 7(3), 267- 275.

Hedberg, J. G., Harper, B. M. \& Brown, C. (1993). Reducing cognitive load in multimedia navigation. Paper presented to Annual Convention of the Association for Educational Communications and Technology, New Orleans.

Hooper, K. (1988). Interactive Multimedia Design. Tech. Report \#13. Cupertino, CA: The Multimedia Lab. Apple Computer Inc.

Kolb, D. A., Rubin, I. M. \& McIntyre, J. M. (1979). Organizational Psychology - a book of readings. (3rd ed). Sydney: Prentice-Hall.

Lee, Yung-Bin B. (1992). Effects of learning style in a hypermedia instructional system. Proceedings of the Association for Educational Communications and Technology. (14th ed.), 505-509.

Merrill, M. D. (1991). Constructivism and Instructional Design. Educational Technology, 31(5), 45-53. 
Murphy, S. (1992). Navigation: How learners find their way through computer based instructional material. Research report, Wollongong: Faculty of Education, University of Wollongong.

Orr, K. L. \& Davidson, G. V. (1992). The effects of group computer-based instruction and learning style on achievement and attitude. Journal of Educational Multimedia and Hypermedia, 1, 781-792.

Preece, J. \& Davies, G. (1992). Multimedia: Some Promises, Some Problems and Some Issues in Human-Systems Interaction. Journal of Educational Multimedia and Hypermedia, 1, 259-366.

Riddle, J. (1992). Distance education and learners' differences: An examination of different instructional procedures designed to accommodate the learning characteristics of field-dependent and fieldindependent learners. Proceedings of the Association for Educational Communications and Technology. (14th ed.) pp 625-636.

Schmeck, R. (1988). Learning Strategies and Learning Styles. New York: Plenum Press.

Stanton, N. \& Baber, C. (1992). An investigation of style and strategies in self directed learning. Journal of Educational Multimedia and Hypermedia, $1,147-167$.

Stanton, N. A. \& Stammers, R. B. (1990). Comparison of structured and unstructured navigation through a CBT package. Computers and Education, 15 (1-3), 159-163.

Sweller, J. (1988). Cognitive load during problem solving: Effects on learning. Cognitive Science, 12, 257-285.

Tucker, R. N. (1990). Navigation: Or the Art of Knowing (where you are). In J. Baker, \& R. Tucker, (eds.), The Interactive Learning Revolution: Multimedia in Education and Training. London: Kogan Page.

Volker, R. (1992). Application of constructivist theory to the use of hypermedia. Proceedings of the Association for Educational Communications and Technology. (14th ed.) pp 869-873.

Williams, M. D. \& Dodge, B. J. (1993). Tracking and analysing learnercomputer interaction. Journal of Educational Multimedia and Hypermedia, 1, 1115-1129.

Williams, M. D. (1992). A comprehensive review of learner-control: the role of learner characteristics. Journal of Educational Multimedia and Hypermedia, 1, 1083-1114.

Wright. P. (1989). Hypertexts as an interface for learners: Some human factor issues. In Jonassen, D. H. \& Mandl, H. (eds), pp 169-184. 
Additional references

Arnone, M. P. \& Grabowski, B. L. (1992). Curiosity as a personality variable influencing learning in an interactive environment. Journal of Educational Multimedia and Hypermedia, 1, 79-114.

Beichner, R. J. (1993). A multimedia editing environment promoting science learning in a unique setting - A case study. Journal of Educational Multimedia and Hypermedia, 1, 60-67.

Campagnoni, F. R. \& Ehrlich, K. (1989). Information retrieval using a hypertext-based help system. ACM Transactions of Office Information Systems, 7(3), 271-291.

Chi, M. T. H, Glaser, R. \& Rees, E. (1982). Expertise in Problem solving. In R. Sternberg (ed), Advances in the Psychology of Human Intelligence. Englewood Cliffs, NJ: Lawrence Erlbaum.

Clarke, J. (1990). Designing CAL programs to cater for different learning styles. In A. McDougall \& C. Dowling (eds), Computers in Education. North Holland: Elsevier Science Publishers.

Gagne, R. M. (1985). The Conditions of Learning. (4th ed) New York: Holt, Rinehart \& Winston.

Grabowski, B. L. \& Curtis, B.(1991). Information, Instruction and Learning: A Hypermedia perspective. Performance Improvement Quarterly, 4(3), 2-12.

Hannafin, M. J. \& Hooper, S. (1989). An Integrated Framework for CBI Screen Design and Layout. In Computers in Human Behaviour. Pergamon Press.

Honebein, P. C., Carr, A. \& Duffy, T.(1992). The effects of modelling to aid problem solving in computer-based learning environments. Journal of Educational Multimedia and Hypermedia, 1, 373-406.

Nielson, J. (1990). The art of navigating through hypertext. Communications of the ACM, 33(3), 297-310.

Pridemore, D. R. \& Klein, J. D. (1992). Learner control of feedback in a computer lesson. Journal of Educational Multimedia and Hypermedia, 1, 803-808.

Resnick, L. B. (1989). Instructional Design. In M. Eraut (ed.), The International Encyclopedia of Educational Technology. New York: Pergamon Press.

Salomon, G. (1977). Interaction of Media, Cognition and Learning. In D. Perkins \& B. Leondar (eds.), The Arts and Cognition. Baltimore: John Hopkins University.

Salomon, G. (1981). Communication and Education: Social and Psychological Interactions. Beverley Hills, CA: Sage Publications.

Author: Gwyn Brickell is a postgraduate research student in the Interactive Multimedia Masters Program at the University of Wollongong. He also coordinates science at a local Technology High School.

Please cite as: Brickell, G. (1993). Navigation and learning style. Australian Journal of Educational Technology, 9(2), 103-114.

http:/ / www.ascilite.org.au/ajet/ajet9/ brickell.html 